\title{
COMPORTAMIENTO DE CULTIVARES DE NARANJO Y MANDARINO RESPECTO A CANCROSIS EN LA ZONA CENTRAL DE SANTA FE
}

\author{
Favaro, M.A. ${ }^{1 ;}$ Peretti, R. ${ }^{1}$; Marano, M.R. ${ }^{2}$; \\ GARIGLIO, N.F. ${ }^{1} \&$ RISTA, L.M. ${ }^{1}$
}

\begin{abstract}
RESUMEN
Con el objetivo de analizar el comportamiento de diferentes cultivares de naranjo y mandarino respecto a la cancrosis bacteriana en la región central de Santa Fe, se calculó la incidencia y severidad de la enfermedad en hojas de la brotación primaveral, estival y en frutos de la estación de crecimiento 2013/14. Se utilizó un diseño experimental completamente aleatorizado con 10 repeticiones por cultivar. Los datos se analizaron a través del Análisis de la varianza y test de Tukey, utilizando el Programa InfoStat. Además se analizaron los datos meteorológicos de la zona en conjunto con la fenología durante la estación de crecimiento. Los naranjos 'Washington Navel' y 'Lanelate' presentaron el peor comportamiento frente a la cancrosis mientras que los naranjos 'Midknight', 'Delta Seedless', 'Valencia late' y 'Salustiana' se ubicaron en un nivel intermedio. Los frutos del mandarino 'Clemenules' presentaron un muy buen comportamiento, pero sus brotes se vieron severamente afectados. El mandarino 'Okitsu' fue el cultivar más resistente.

Palabras clave: Xanthomonas, citri subsp, citri, incidencia, severidad, cultivares, fenología.
\end{abstract}

\section{SUMMARY}

Incidence and severity of citrus canker on different orange and mandarin cultivars at the central area of Santa Fe (Argentina).

In order to analyze the behavior of different orange and mandarin cultivars against citrus bacterial canker in Central Santa Fe, the incidence and severity of the disease were calculated in leaves and fruits of 4 selected branches per tree during spring and summer 2013/14. A complete randomly experimental design with ten replicates per cultivar was used. Data were analyzed using Analysis

1.- Dpto. de Producción Vegetal, Facultad de Ciencias Agrarias (UNL). Kreder 2805. (3080) Esperanza, provincia de Santa Fe. Tel-Fax +54 (3496) 426400. Email: mfavaro@fca.unl.edu.ar

2.- Instituto de Biología Molecular y Celular de Rosario (IBR-CONICET), Facultad de Ciencias Bioquímicas y Farmacéuticas, Universidad Nacional de Rosario. Ocampo y Esmeralda. (2000) Rosario, provincia de Santa Fe. Manuscrito recibido el 26 de septiembre de 2014 y aceptado para su publicación el 4 de noviembre de 2014. 
M. A. Favaro et al.

of variance and means separated by the Tukey's test, through InfoStat Software. Meteorological and phenological data were analyzed in order to explain disease behavior. Between oranges, 'Was'Washington Navel' and 'Lanelate' showed the highest incidence of citrus canker, while 'Midknight', 'Delta Seedless', 'Valencia late' and 'Salustiana' showed intermediate incidence and severity values. The fruits of 'Clemenules' mandarin showed low incidence of canker but their shoots were severely affected. 'Okitsu' mandarin was the most resistant cultivar to citrus canker.

Key words: Xanthomonas, Citri subsp, incidence, severity, cultivars, phenology.

\section{INTRODUCCIÓN}

Numerosos estudios fenológicos, fisiológicos y de comportamiento productivo han demostrado que la zona central de la provincia de Santa Fe presenta condiciones agroecológicas adecuadas para la producción de cítricos (21, 22, 23). Sin embargo, el último Censo Nacional Agropecuario (2002) registró sólo 504 ha de frutales cítricos en la provincia, principalmente naranjas $(78 \%)$ y mandarinas (19\%) (18). Para extender la producción de estos frutales, se hace necesario conocer la adaptación de los diferentes cultivares, así como la información referente al comportamiento frente a las enfermedades más importantes de los cítricos.

La cancrosis A o Asiática producida por Xanthomonas citri subsp. citri ( $X$. citri), es la forma más severa y más ampliamente diseminada de CBC (17). X. citri es una bacteria hemibiotrófica capaz de infectar frutos, hojas y ramas (13). La temperatura óptima para el desarrollo de los síntomas es de $28-30^{\circ} \mathrm{C}(28)$, mientras que las temperaturas bajas ejercen un efecto negativo. Las infecciones de las hojas ocurren principalmente vía estomas y heridas causadas por tormentas, poda, o por insectos como el minador de los cítricos $(13,24)$. Las hojas más susceptibles a la infección de $X$. citri son aquellas que se han expandido entre un 50 a $100 \%$ de su tamaño final $(12,13)$, mientras que el período más crítico para la infección en frutos es durante los noventa días posteriores a la caída de los pétalos (15).

Una vez en el interior del tejido, las células de $X$. citri se multiplican en los espacios intercelulares envueltas en una matriz de polisacáridos (30). Cuando las condiciones son adecuadas, aproximadamente 7 días después de la inoculación, aparecen los primeros síntomas en el envés de las hojas como pequeñas ampollas sobreelevadas, de aspecto aceitoso o húmedo (13). Las lesiones consisten en la hiperplasia del tejido del mesófilo que luego evoluciona a pústulas con aspecto eruptivo y corchoso. La bacteria sobrevive principalmente en lesiones de hojas y ramas. Las lluvias que causan la acumulación de agua en las hojas y ramas, sumadas a velocidades de viento superiores a los $28 \mathrm{~km} / \mathrm{h}$, facilitan su dispersión (16).

Cuando la cancrosis es considerada enfermedad endémica, deben ponerse en práctica programas de manejo integrado. En Argentina, luego de intentos poco exitosos de erradicación de plantaciones afectadas, se intenta "convivir con la enfermedad". Esta estrategia consiste en la selección de cultivares poco susceptibles, producción de plantas libres de la enfermedad en viveros, en combinación con pulverizaciones de

80 | Revista FAVE - Ciencias Agrarias 13 (1 - 2) 2014 